\title{
Etymological Vs. Literal Teaching of Idiomatic Expressions in an EFL Context: No Difference in Retention of Idioms Constituents
}

\section{Ali Reza Atashpanjeh ${ }^{1 *}$, Mehdi Haseli Songhori ${ }^{2}$}

\section{* Correspondence: \\ a_atashpanjeh@yahoo.com \\ 1. Department of English Language, \\ School of Medicine, Zahedan \\ University of Medical Sciences and \\ Health Cares, Zahedan, Iran. \\ 2. Department of English Language, \\ Islamic Azad University of Zahedan, \\ Iran}

Received: 8 November 2019

Revision: 22 March 2020

Accepted: 13 May 2020

Pblished online: 20 September 2020

\section{Abstract}

In an attempt to profile the effect of two methods of teaching Second Language (L2) idioms, Etymological vs. Literal, a group of English Language learners $(n=14)$ were selected to participate in this study. It was a within-subjects study and the chosen idioms were taught in 6 sessions regarding the two methods to the same group (each method in three sessions). In the first three sessions, 30 idioms were taught literally. In the next three sessions, 30 other idioms were taught etymologically. Then, their post-tests were performed immediately after instruction. Finally, a delayed posttest was conducted after one-week interval to find out the amount of retention of idioms' constituents. The results indicated no significant effect in the retention and later production of L2 idioms and their constituents in English as a Foreign Language (EFL) context. Following either of these methods regarding time and goals of instruction can be considered as an implication of this study.

Keywords: idiom, idiom instruction, etymology vs. literal teaching method 


\section{Introduction}

Idioms are ubiquitous in any natural language and they paint the discourse with their colorful meanings. According to Brenner (2011) and Vasiljevic (2015), English language contains over 10,000 idioms and the competence in understanding and using idioms is a defining predictor of native-like proficiency in English. Put it another way, Liontas (2017) believes that idiomatic competence indicates that a language learner is an effective and competent speaker.

Considering the importance and pervasiveness of idioms in English language learning and teaching, they yet present one of the most challenging and demanding issues not only for ESL/EFL learners in learning English (Beloussova, 2015; Ghorbani, 2017; Razmjoo et al., 2016), but also for young native speakers of English who are learning idioms in their first language because of their lack of the intellectual capacity to realize that words can have multiple meanings (Liontas, 2018).

As Liu (2003, p. 671) righty states, idioms are "notoriously difficult" for any English learner, especially EFL learners because of their "rather rigid structure, quite unpredictable meaning, and fairly extensive use." The learning challenge mostly lies in the comprehension of idioms because EFL learners have been found to resort to figuring out the meaning of idioms based on the literal meaning of words that constitute them which most often is not very helpful (Dovchin, 2020).

\section{1 Statement of the Problem}

Due to the pervasiveness of idioms in everyday give-and-take and the difficulty in their learning and comprehension, scholars in the field of second/foreign language learning and teaching have introduced a handful of strategies to help solve the problem. Some of these strategies include providing definitions, etymological elaboration, clarifying meaning through pictures, translating idioms into learners' first language, memorization, and so on (Boers et al., 2007; Mousavi et al., 2016; Razmjoo et al., 2016).

Etymological origin exploration is one of the effective strategies in not only L2 vocabulary instruction, but also in teaching idioms (Liontas, 2018). Etymological elaboration has been defined as the association of idioms with information regarding their origin and source domains. Although this strategy has been of particular interest in idiom instruction, there is a lacuna in L2 idiom pedagogy vis-à-vis its effectiveness compared to literal teaching of idioms to L2 learners. Thus, this study attempts to help fill this gap through the implementation of these two modes of idiom instruction, namely etymological elaboration and literal translation.

\subsection{Research Questions}

The current study intends to address the following research questions:

1. Comparing to literal approach, can an etymological elaboration approach be effective in facilitating the retention of L2 idioms for EFL students?

2. Comparing to literal approach, can an etymological elaboration approach be effective in facilitating the retention of constituent parts of L2 idioms for EFL students?

\subsection{Research Hypotheses}

Based on the above research questions, the following null hypotheses were suggested:

1. Etymological elaboration approach is not effective in facilitating the retention of L2 idioms for EFL students comparing to literal approach.

2. Etymological elaboration approach is not effective in facilitating the retention of constituent parts of L2 idioms for EFL students comparing to literal approach.

\section{Literature Review}

Idioms as a type of multiple word units (MWUs) have both literal and figurative meanings. Since literal meanings of the individual constituents of an idiom, in most cases, cannot be helpful in predicting its figurative meaning, idiom processing and comprehension presents "special difficulty to L2 learners, as well as a never-ending challenge for ESL teachers" (Cooper, 1999, p.233). Kick the bucket and bite the dust (i.e. to die) are two typical examples of idioms with a figurative meaning which cannot be decoded through their literal meanings. Providing the etymology (origin and 
background) of idioms to help for better comprehension and longer retention is an effective approach in teaching target idioms (Boers, 2000; Boer et al., 2004).

According to Liu (2008), there are at least six reasons behind teaching idioms in foreign language classes: 1) language use is governed by two complementary operating principles: the open choice principle and the idiom choice principle (Sinclair, 1987). The open choice principles constitute a repertoire of morphemes, words, and phrases that are combined to build up a text. On the other hand, based on the idiom choice principle, the speaker uses a large number of pre-constructed phrases including idioms in their communication. Therefore, idioms play an essential part in language development. 2) Since idioms convey messages so effectively that non-idiom expressions cannot, they are very effective and invaluable tools in communications (Fernando, 1996; Moon, 1998). 3) In addition to help L2 learners communicate more effectively, idioms and formulaic expressions assist L2 learning by offering learners language input that can be segmented and analyzed (Bardovi-Harlig, 2002; Wood, 2010; Wray, 2000). 4). Idioms are culture bound and culture specific. Through learning idioms, learners find an opportunity to acquire information about the target culture and community. 5) Learning colloquial idioms used very frequently in casual conversations create opportunity to communicate more effectively while practicing the target language in real life situations. 6) The learner mastery of L2 idioms likely means a higher L2 proficiency level (Yorio, 1989), and the more the number of acquired idioms are, the more effective communication will happen (Duquette, 1995; Schmitt, 2004). However, idioms as a class of MWUs have some distinguishing characteristics which differentiate them from other groups of language units.

According to Thiel (1979, p.23), "sooner or later, lack of precise idiomatic usage will betray the foreign background even of a speaker with an excellent grammatical knowledge, vocabulary, and pronunciation.” Knowing the etymology of idioms is helpful in the comprehension and retention of them (Boers et al., 2000, 2004; Pierson, 1989; Saffarian, et al., 2013; Szczepaniak \& Lew, 2011). Therefore, there are a reliable number of evidence confirming the importance of idiom etymological familiarity in foreign/second language learning settings.

Moreover, there are several studies that have focused on Iranian EFL learners and idiom comprehension (Baleghizadeh \& Bagheri, 2010; Ghaderi \& Afshinfar, 2014; Golaghaei \& Kakolian, 2015; Reisi Gahroei \& Haghverdi, 2012; Zolfagharkhani \& Ghorbani Moghadam, 2011). These studies revealed that etymological elaborations positively affect idiom comprehension. In such studies, variability in the types of idioms should be considered cautiously. In the following section, the rationale for selecting idioms in this study were explained.

\subsection{Criteria for Defining Idioms}

"Differences between word combinations such as free phrases, restricted collocations, and idioms - all crucial to the foreign learner - are neither presented consistently nor explained adequately in reference works" (Cowie, 1998, p.218). In an effort to define the criteria of idioms, Grant and Bauer (2004, p.44) suggested three categories of idiomatic expressions: core idioms (non-compositional MWUs (multi-word units), the meaning of which cannot be predicted from the meaning of their constituent parts, for example, shoot the breeze), figuratives (MWUs with metaphors) and ONCEs (one non-compositional element). They concluded that the key criterion to define an idiom from MWUs is its non-compositionality. They proposed a three-step test (Table 1) to differentiate MWUs as either a core idiom or a figurative/compositional expression.

Table 1. A three-step test to determine a core idiom (adapted from Grant and Bauer, 2004, p. 52).

Step1. Is the meaning of the MWU retained if you replace each lexical word in the MWU with its own definition? $\mathrm{Y}=$ compositional $\quad \mathrm{N}=$ non-compositional

Step 2. Is it possible to understand the meaning of the MWU by recognizing the untruth and pragmatically reinterpreting it in a way that correctly explains the MWU?

$\mathrm{Y}=$ figurative $\quad \mathrm{N}=$ non-figurative

Step 3. Is there only one word in the MWU which is either not literal or non-compositional?

$\mathrm{Y}=\mathrm{ONCE}$ (one non-compositional element)

$\mathrm{N}=$ more than one element is non-compositional

$\square$ If all the three answers are NO, the MWU is a 'core idiom.'

$\square$ If any of the three answers is YES, the MWU is a not a 'core idiom' (may be a figurative, or a ONCE). 
As Table 1 shows, if all the answer of a MWU is NO, then it is considered as a core idiom; however, if any of the answers is YES, the MWU should be considered as a figurative or ONCE expression. In this study, a sample of core idioms (non-compositional MWUs) was selected to be taught.

\subsection{Why Etymological Elaboration of Idioms as a Pedagogical Approach}

Ross (1969) defines etymology as the scientific study of the origins and forms of words. Application of etymology to L2 vocabulary learning has long been embraced by ESL specialists. Pierson (1989 as cited in Zhang 2009) tried to get through meaningful vocabulary learning in ESL by incorporating the etymology elaboration of the words into his instruction at the Chinese University of Hong Kong. Even though Pierson did not report empirical data for his study, his pedagogical approach to teaching the words' origin has been accepted and further studies (Boers \& Demecheleer 1997; Boer et al., 2001, 2004; Bulut, \& Celik-Yazici, 2004; Gibbs, 1990, 1994; Gibbs et al., 1989; Guo, 2008) followed his pedagogical proposal.

In a series of large scale studies conducted by Boers et al. from 1998 to 2004 on the effects of etymological elaboration on idiom acquisition, it was revealed that introducing both the literal and etymological usage of an idiom to learners can effectively contribute to their comprehension and retention of idioms, but there are no studies, known to the author, which have attempted to analyze the effect of etymology elaboration on the retention of idioms constituents as MWUs (e.g. the retention of prepositions). The current study conducted, first to examine the effect of the etymology elaboration on the comprehension and retention of idioms, and second to find out whether this type of elaboration can help learners to retain idioms' constituents.

\section{Methods}

\subsection{Research Design}

In this study, since there was only one group which was exposed to both experiments, therefore, a within-subjects design was employed. The materials which were applied were an OPT test and four researcher- made tests. Regarding tests, a pre-test, treatment, post-test design was used to conduct this study. The obtained data were analyzed using descriptive statistics and one-way repeated measures ANOVA. Concerning the variables of interest, the students' English language proficiency, here intermediate level, was as the independent variable, and the dependent variables were the students' scores in three different intervals after treatment.

\subsection{Participants}

This study was conducted by recruiting 14 fourth semester English Language students (females, $n=10$, and males, $n=$ 4) aged between 22 to 38 years, studying at Islamic Azad University, Zahedan Branch, Iran. All the participants were non-native speakers of English language. They were Persian speakers who did not have any experience in learning English idioms. They were intermediate language learners who had been selected from a population of 50 language learners through an OPT (Oxford Placement Test). The rationale for selecting this group for the current study was their availability. They were the researchers' students.

\subsection{Instruments}

The materials used in this study were an OPT test, and four researcher- made tests, 1) a 30-item multiple choice pretest involving all 30 to-be-taught idioms, 2) a 30-item multiple choice posttest based on idioms taught literally, 3) another 30-item multiple choice posttest based on idioms taught etymologically, and finally, a 30-item completion test.

First, to determine the homogeneity level of the students, an OPT test (Version. 1.1) including 60 items in multiplechoice format was used. The second one was a test of 30 multiple choice items to elicit the EFL learners' knowledge of idioms as a pretest. The third test was a 30-items posttest to measure the EFL learners' knowledge of idioms which have been taught literally. The fourth test was another 30-items posttest to evaluate the same subjects' knowledge of idioms which have been taught etymologically, and the fifth one was a completion test, as a delayed posttest, including 30 items to test the retention of the idioms' constituents after etymological elaborations.

\subsection{Procedures}

\subsubsection{Idiom Selection}

As the first step, a number of 60 idioms were selected to be taught during treatment. There were two criteria for selecting the target idioms, first they should be from core idioms category. These idioms were non-compositional 
MWUs which their meanings cannot be deciphered from their constituent parts (Grant \& Bauer, 2004). They were selected from The Oxford Dictionary of Idioms (Siefring, 2004), Collins Cobuild Dictionary of Idioms (2006), and American Heritage of American of Idioms (1997) with rich etymological origins. Then, the selected idioms were checked with $w w w . c o r p u s . b y u . e d u$ to extract their frequency in the real life situations. The most frequent idioms $(\mathrm{n}=$ 60) were prioritized to be included in the teaching sessions and tests, respectively. Out of 60 selected idioms, a number of 30 idioms were finalized to be taught literally, and the other 30 idioms etymologically to the same group of subjects.

\subsubsection{Data Collection}

A pre-test, treatment, post-test design was used to conduct this study. Participants, a group of 14 language learners, were taught English idioms using two methods: In the first 3 sessions, 30 selected idioms, out of which 15 idioms were chosen to be included in our posttest, were taught based on the traditional approach; that is teaching idioms literally without focusing on their origins. Afterwards, following the second method, another 30 idioms with etymological elaborations, out of which 15 were chosen for our posttest, were taught to the same group. These idioms were also taught in three sessions. Each session almost took one and half hour. The selected idioms were presented via Video Projection. For each idiom, a PowerPoint Slide was prepared. In the literal slides, the idiom, its meaning, and one or two examples were presented; on the other hand, in etymology slides, the idiom and the story behind that idiom- its etymology- was presented (Figure 1). There were no paper and pencil materials and note taking for subjects and they just listened to the instructor.

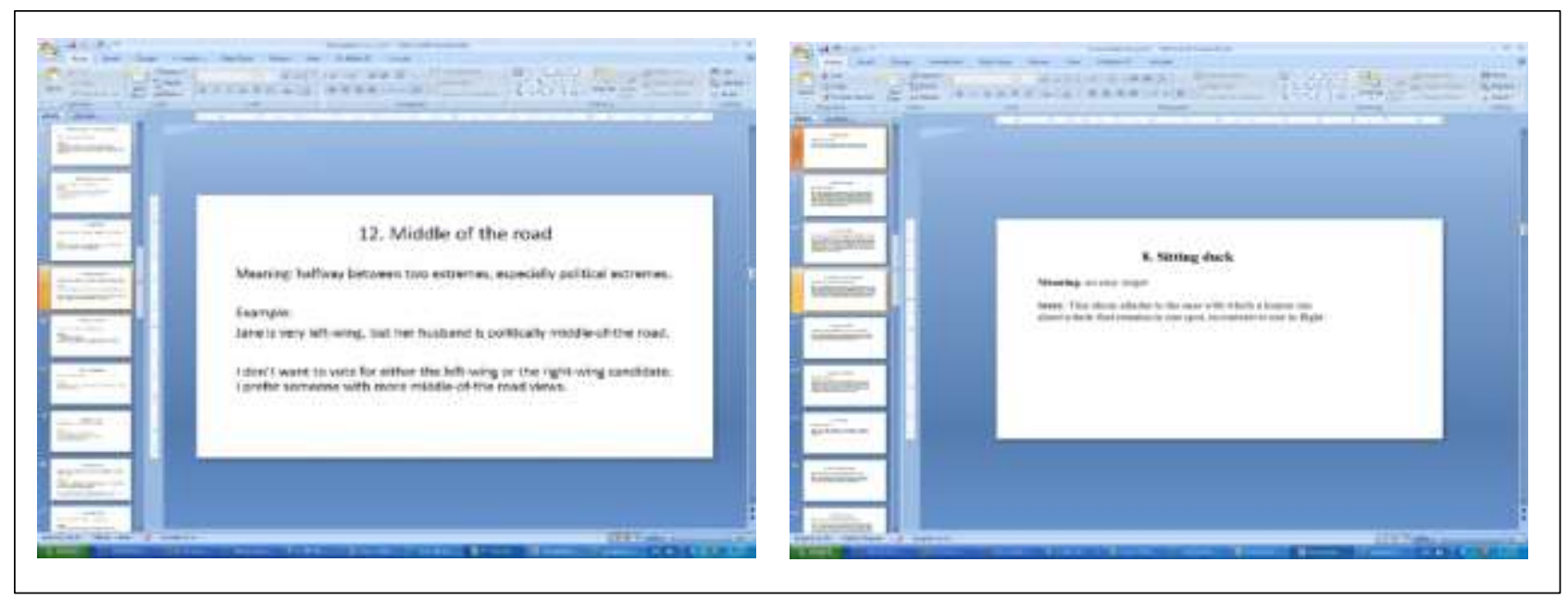

Figure 1. Examples of literal and etymological slides

In the first three sessions, 30 idioms were taught literally. Then, the first post-test was performed immediately after instruction to examine the effect of literal teaching approach on facilitating the retention of L2 idioms for EFL learners. Examples of pre-post tests were as follow:

Instruction: Choose the best answer.

Example 1: You deliberately choose unknown actors, although India is a country where the star system is very much
a. alive and kicking
b. whisker
c. deaf as an adder
d. out of the blue

Example 2: As leader I was also navigator-in-chief and felt it would be good for the group to discover parts of the island well.
a. off the beaten track
c. out of the ark

b. with open arms

d. by the back door 
In the next three sessions, 30 other idioms were taught etymologically. Afterwards, the second post-test was performed immediately after instruction to examine the effect of etymological teaching approach on improving the retention of L2 idioms for EFL learners. Eventually, after one-week interval, a delayed posttest was conducted to find out whether this type of elaboration can help learners to retain idioms' constituents. An example of the delayed posttest was as follow:

Instruction: Based on the definitions in the parentheses, write the appropriate idiom in blanks.

\section{Example:}

Everyone else on the committee quit, leaving me (alone and helpless)

The learners had to produce the correct idiom with its correct constituents (e.g. correct preposition, verb, and adjective). Finally, the two sets of scores were compared and analyzed using one-way repeated measures ANOVA.

\subsection{Data Analyses}

De-identified data from the pre and post- tests were entered into SPSS Software Ver. 20 and analyzed. Descriptive statistics and one-way repeated measures ANOVA were run to analyze the collected data and the conclusions were drawn on the significance in the effectiveness of etymological elaboration compared to traditional literal instruction. The probability for statistical significance was set at $\mathrm{p}>0.05$.

\section{Results}

A one-way repeated measures ANOVA was conducted to compare scores on the effect of etymological elaboration in facilitating the retention of L2 idioms for EFL students compared to literal approach. The results indicated that there was no significance effect regarding two teaching methods, Wilks' Lambda $=.43$, F $(1,27)=34.44$. p $<.05$, multivariate partial eta scored $=.56$. The means and standard deviations are presented in Table 1. Interestingly, both methods have been effective comparing pre and posttests. The mean of pre and posttest for literal teaching method was 5.85 and 9.57 and for etymological teaching method was 6.78 and 9.71 , respectively.

Table 1. Descriptive Statistics for Literal and Etymological Teaching Methods

\begin{tabular}{llccc}
\hline & Teaching methods & Mean & Std. Deviation & $\mathrm{N}$ \\
\hline pretest & Literal & 5.8571 & 3.20713 & 14 \\
& Etymological & 6.7857 & 2.48623 & 14 \\
\multirow{3}{*}{ posttest } & Total & 6.3214 & 2.85519 & 28 \\
& Literal & 9.5714 & 2.95386 & 14 \\
& Etymological & 9.7143 & 2.89372 & 14 \\
& Total & 9.6429 & 2.87021 & 28 \\
\hline
\end{tabular}

Then, to depict the effect of literal and etymological teaching methods regarding pre and posttest, the two sets of scores were compared. As figure 2 indicates, in both methods, the mean of posttest scores is higher than the pretest scores. 


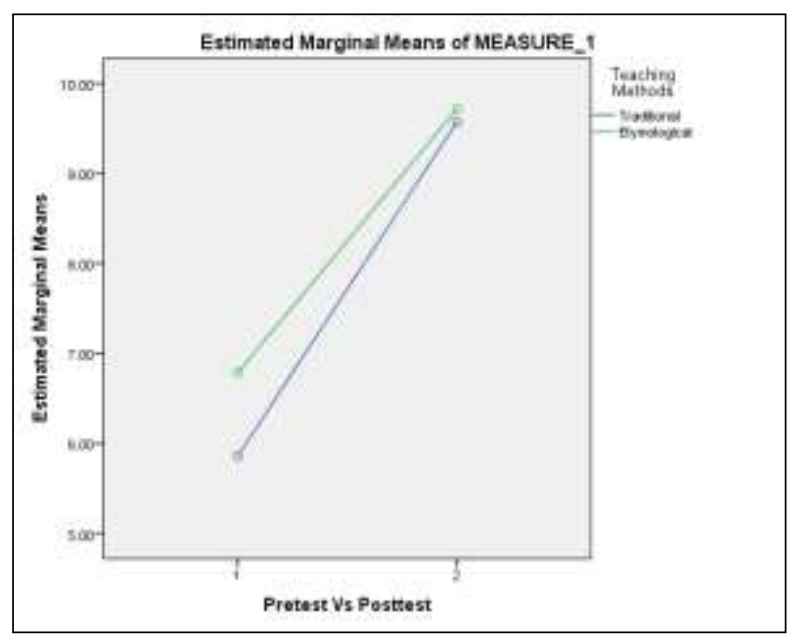

Figure 2. Plot for comparing literal and etymological teaching methods

Finally, to answer the second research question that is whether etymological elaboration method can be more effective in facilitating the retention of constituent parts of L2 idioms for EFL students compared to literal method, the results related to the delayed posttest were analyzed (Table 2). Out of 327 answered questions, $70.65 \%(n=231)$ were left with no answer which expresses the learners' inability to produce the correct idiom. Furthermore, among the tests with answer, $17.12 \%(n=56)$ were wrong which again indicates that the subjects have been unable to produce correct idiom and consequently its constituents. Only $12.23 \%(n=40)$ of answers were correct, that is both the idiom and its constituent were produced correctly. The results showed that etymological teaching method was not an effective teaching method compared to literal one in facilitating the retention of constituent parts of L2 idioms.

Table 2. Frequency and percent of answers for completion posttest

\begin{tabular}{cclc}
\hline & \multicolumn{1}{c}{ Frequency } & Percent \\
\hline No Answer & 231 & Etymological, $\mathrm{n}=114$ & 70.65 \\
& & Literal, $\mathrm{n}=117$ & 12.23 \\
Correct Answer & 40 & Etymological, $\mathrm{n}=22$ & 17.12 \\
Wrong Answer & 56 & Literal, $\mathrm{n}=18$ & 100 \\
& & Etymological, $\mathrm{n}=34$ & 100 \\
\hline
\end{tabular}

\section{Discussion}

This study set out to explore the effect of etymological teaching method on facilitating the comprehension and retention of L2 idioms compared to traditional literal method. A group of 14 English language students participated in this study. The selected idioms were taught to the same group applying both methods separately. The findings suggest no significant difference in facilitating the comprehension and retention of L2 idioms regarding applying these two methods.

A growing body of evidence supports the advantage of application of etymology to learning L2 vocabulary and idiom learning (Bagheri \& Fazel, 2010; Coryell, 2012; Zarei \& Rahimi, 2012). Pierson (1989), for instance, proposed a pedagogy with etymology instruction at the Chinese University of Hong Kong. The findings revealed that introducing 
etymology is an effective method in learning L2 idioms. The findings of Pierson's study, of course, are not in line with the present study in which we could find no advantage for introducing the etymology of idioms.

With several large-scale studies, Boer et al. $(2000,2004)$ have examined the effectiveness of etymological elaboration as a pedagogical approach in L2 idiom instruction all of which confirmed the positive effects of access to etymological information. In their study, two groups of learners, experimental and control, were examined. The experimental group had access to etymological information while the control group did not have. A post-test and a delayed post-test were administered to measure the effects of the etymology instruction on L2 idiom learning. The findings showed that the experimental group acquired significantly more idioms than the control group, while the results of the current study were not in agreement with Boers' studies. The results of the present study should be reported by cautious, and may not be generalizable, since the number of subjects was limited. Moreover, the same subjects participated in both phases of the study. There is no guarantee that the two methods may have affected and interacted with each other.

Verbal information along with etymological elaboration of an idiom facilitates learners' comprehension and recall (Zhang, 2009). Iranian EFL upper-intermediate learners who received idioms with the etymological elaborations outperformed the control group, that is, it was significantly effective on the learners' comprehension and retention (Baleghizadeh \& Bagheri, 2010). In the present study, even though etymological elaboration was helpful for learning idiomatic expressions, the results of the delayed posttest indicated that, regarding retention, there was no significant difference between the two method of teaching idioms, i.e., etymological vs. literal. There were a couple of intervening factors that influence on the results and were not under the control of the researchers such as learners' motivation for learning and even answering the posttest/delayed posttest. If the subjects have not taken the tests seriously, as the tests were not a part of their midterm or final exams, they may have not been motivated enough to answer the questions.

Synergy of pictures and etymological elaboration is more effective than only teaching idioms etymologically (Ghorbani, 2017). He suggested that the etymological elaboration can be useful, but the learners will have greater idioms retention, if teaching idioms go with related funny pictures. The combination of visual and etymological teaching mode has a significant effect on learning idiomatic expressions (Golaghaei \& Kakolian, 2015). The findings of the current study partially confirm the results of the abovementioned studies. In this study, providing etymological explanations also improved the degree of subjects' achievement. The current findings substantiate Zolfagharkhani and Ghorbani Moghadam's (2011) study in which the impact of etymology instruction on vocabulary learning compared to traditional method was reported. Reisi Gahroei and Haghverdi (2012) study also supports etymological elaborations in teaching idiomatic expressions.

Fotovatnia and Khaki (2012) also highlighted the importance of the effect of using pictures vs. translation equivalents and English definitions on the idiom learning of Iranian EFL undergraduates. They concluded that teaching idioms through related pictures promotes learning idioms compared to other techniques applied in their study. Moslehi and Rahimi (2018) reported the effectiveness of role play in promoting idiomatic competence compared to written practice. They stated that Iranian EFL learners' idiomatic knowledge significantly improved via role play. All in all, the findings of the related literature indicated that applying other techniques and methods in addition to literal method helps the learning and retention of new idiomatic expressions.

In another study by Saffarian et al. (2013), the presence of pictures in the input had a negative impact on the learners' performance. Learners could remember the related pictures, but not the precise lexical composition of the idioms. Their study may be considered as consistent with Szczepaniak and Lew (2011) study since pictorial elucidation had a significant effect on meaning retention of idioms only in a short-term. Therefore, involving some elements such as the presence of pictures may not only improve, but affect negatively. In these cases, picture presentation has acted as a distractor in learning idiomatic expressions. It indicates the complexity of teaching and learning careers. On the other hand, Ghaderi and Afshinfar (2014) compared the effects of animated versus static funny pictures on Iranian intermediate EFL students' intake and retention of idioms. The results showed that learners had a higher intake and retention of idioms which have been taught through animated pictures.

Variability in the results related to teaching idiomatic expressions shows that great care must be taken in our teaching methods, since the number of factors involved varies depending on the number of classes held and learners attended. The findings of this study have significant pedagogical implications so that if etymological elaboration is effective, then instructors can apply this approach in their classes. Moreover, if this approach proves to be effective, researchers can apply etymological elaboration through other media and tools like online instruction, CALL, or even through visual aids to find out the effect of each one of these factors on comprehending and retaining the idioms. There are 
some limitations in this study. First, the sample size of this study $(n=14)$ can be considered as its major limitation. Then, the selection criterion which was based on participants' availability can be regarded as the second limitation. Finally, the number of taught idioms and the number of instruction sessions may affect the results.

\section{Conclusion}

As mentioned previously, there were a corpus of studies that support introducing etymology as an effective method in learning L2 vocabulary and idiom, but the current study could not find any significant effect of accessing etymological information on the retention and later the production of idioms and their constituents. Both treatments were effective enough so that the mean scores of two types of treatment was higher than the starting point. It could just confirm that etymology instruction is an effective method for teaching L2 idioms without any significant priority to the literal method. Even though these results differ from previously published studies in that all of them reported the importance of etymological elaborations in learning idiomatic expressions, we think that it is advisable to teach idioms through different modalities and techniques. Each mode may have its own advantage over others.

\section{References}

Ammer, C. (Ed.) (1997). The American Heritage of American of Idioms. Boston: Forbes Inc.

Bagheri, M. S., \&Fazel, I. (2010). Effects of etymological elaboration on EFL learners' comprehension and retention of idioms. Journal of Pan-Pacific Association of Applied Linguistics, 14(1), 45-55. http://citeseerx.ist.psu.edu/viewdoc/download?doi=10.1.1.920.630\&rep=rep1\&type=pdf

Baleghizadeh, S., \& Mohammad Bagheri, M. (2010). The effect of etymology elaboration on EFL learners' comprehension and retention. 3L: The Southeast Asian Journal of English Language Studies, 18(1), 23-33. file:///C:/Users/ASUS/AppData/Local/Temp/946-1810-1-SM.pdf

Bardovi-Harlig, K. (2002). A new starting point? Investigating formulaic use and input in future expressions. Studies in Second Language Acquisition, 24(2), 189-198. doi: 10.2307/44486610

https://www.jstor.org/stable/44486610

Beloussova, V. (2015). Idiom learning materials for Estonian secondary school students. Unpublished MA thesis. Estonia, University of Tartu.

Boers, F. (2000). Metaphor awareness and vocabulary retention. Applied linguistics, 21(4), 553-571. https://doi.org/10.1093/applin/21.4.553

Boers, F., \& Demecheleer, M. (1997). A few metaphorical models in (Western) economic discourse. https://doi.org/10.1075/cilt.151.10boe

Boers, F., \& Demecheleer, M. (2001). Measuring the impact of cross-cultural differences on learners' comprehension $\begin{array}{llll}\text { of imageable } & \text { idioms. } & \text { ELT }\end{array}$ https://pdfs.semanticscholar.org/16d1/c015583a021284cb7e9dc438e03f98480a6a.pdf

Boers, F., Demecheleer, M., \& Eyckmans, J. (2004). Etymological elaboration as a strategy for learning idioms. Vocabulary in a second language: Selection, acquisition and testing, 53-78. https://doi.org/10.1075/11lt.10.07boe

Boers, F., Eyckmans, J., \& Stengers, H. (2007). Presenting figurative idioms with a touch of etymology: More than mere mnemonics? Language Teaching Research, 11(1), 43-62. https://doi.org/10.1177/1362168806072460

Brenner, G. (2011). Webster's new world American idioms handbook: Houghton Mifflin Harcourt.

Bulut, T., \& Celik-Yazici, I. (2004). Idiom processing in L2: Through rose-colored glasses. The Reading Matrix, 4(2), 105-116. https://pdfs.semanticscholar.org/efa3/4a83f3e42ed1430b6deab4e149b3b57d4fe0.pdf

Cooper, T. C. (1999). Processing of idioms by L2 learners of English. TESOL Quarterly, 33(2), 233-262. doi: 10.2307/3587719 https://www.jstor.org/stable/3587719

Coryell, L. J. (2012). The effectiveness of etymological elaboration as a method of teaching idioms. (Unpublished doctoral dissertation). Department of Educational Theory and Practice. School of Education. University of Albany, State University of New York. 
Cowie, A. P. (1998). Phraseological dictionaries: some east-west comparisons. In Cowie, A. P. (ed.) Phraseology, Theory, Analysis, and Applications, 209-228. Oxford: Oxford University Press.

Dovchin, S. (2020). Language, Social Media and Ideologies: Translingual Englishes, Facebook and Authenticities. Springer.

Duquette, G. (1995). Developing comprehension and interaction skills with idiomatic expressions. In G. Duquette (Ed.), Second language practice: Classroom strategies for developing communicative competence (pp. 35-42). Clevedon, England: Multilingual Matters.

Fernando, C., \& Carter, R. (1996). Idioms and idiomaticity. Oxford: Oxford University Press.

Fotovatnia, Z., \& Khaki, G. (2012). The effect of three techniques for teaching English idioms to Iranian TEFL undergraduates. Theory and practice in language studies, 2(2), 272-281. doi:10.4304/tpls.2.2.272-281

Ghaderi, V., \& Afshinfar, J. (2014). A comparative study of the effects of animated versus static funny pictures on Iranian intermediate EFL students' intake and retention of idioms. Procedia-Social and Behavioral Sciences, 98, 522-531. https://doi.org/10.1016/j.sbspro.2014.03.448

Ghorbani, M. R. (2017). The synergistic effect of funny pictures and etymological elaboration on promoting EFL learners' idiom retention and recall. Journal of Language and Linguistic Studies, 13(1), 146-155. file:///C:/Users/ASUS/Downloads/555-1913-1-PB.PDF

Gibbs J., R. W., Nayak, N. P., \& Cutting, C. (1989). How to kick the bucket and not decompose: Analyzability and idiom processing? Journal of memory and language, 28(5), 576-593. https://doi.org/10.1016/0749$\underline{596 \times(89) 90014-4}$

Gibbs, R. W. (1990). Psycholinguistic studies on the conceptual basis of idiomaticity. Cognitive Linguistics (includes Cognitive Linguistic Bibliography), 1(4), 417-451. doi: https://doi.org/10.1515/cogl.1990.1.4.417

Gibbs, R. W. (1994). The poetics of mind: Figurative thought, language, and understanding. Cambridge University Press.

Golaghaei, N., \& Kakolian, S. (2015). The effect of visual and etymological treatments on learning decomposable idioms among EFL learners. International Journal of Applied Linguistics and English Literature, 4(5), 72-81. doi:10.7575/aiac.ijalel.v.4n.5p.72 http://dx.doi.org/10.7575/aiac.ijalel.v.4n.5p.72

Grant, L., \& Bauer, L. (2004). Criteria for re-defining idioms: Are we barking up the wrong tree? Applied Linguistics, 25(1), 38-61. https://doi.org/10.1093/applin/25.1.38

Guo, S. (2008). Differential effects of etymological elaboration and rote memorization on idiom acquisition in College EFL learners. http://www.celea.org.cn/teic/82/82-52.pdf

Liontas, J. I. (2018). Teaching idiomatic language in context. The TESOL Encyclopedia of English Language Teaching, 1-10. https://doi.org/10.1002/9781118784235.eelt0723

Liu, D. (2003). The most frequently used spoken American English idioms: A corpus analysis and its implications. TESOL Quarterly, 37(4), 671-700. https://doi.org/10.2307/3588217

Liu, D. (2008). Idioms: Description, comprehension, acquisition, and pedagogy. Routledge.

Moon, R. (1998). Fixed expressions and idioms in English: A corpus-based approach. Oxford University Press.

Moslehi, M., \& Rahimi, D. (2018). The effect of role-play through dialogues vs. written Practice on Iranian intermediate EFL learners' knowledge of English idioms. International Journal of Research in English Education, 3(1), 59-67. http://ijreeonline.com/article-1-89-en.html doi: 10.29252/ijree.3.1.59

Pierson, D. H. (1989). Using etymology in the classroom. ELT Journal, 43(1), 57-63. doi: 10.1093/elt/43.1.57

Razmjoo, S. A., Songhori, M. H., \& Bahremand, A. (2016). The effect of two attention-drawing techniques on learning English idioms. Journal of Language Teaching and Research,7(5), 1043-1050. doi: http://dx.doi.org/10.17507/jltr.0705.28 
Reisi Gahroei, F., \& Haghverdi, H. (2012). Impact of teaching the etymology of idioms on Iranian EFL learners' idiom learning. Paper presented at the First International Conference on Research in Teaching English, Translation, and Linguistics (RTETL).

Ross, A. (1969). Etymology. London: Andre Deutsch.

Saffarian, R., Gorjian, B., \& Bavizadeh, K. (2013). The effect of using pictures on EFL learners' retention of body idiomatic expressions. Journal of Comparative Literature and Culture, 2(4), 150-154.

Schmitt, N. (2004). Formulaic sequences: Acquisition, processing, and use (Vol. 9): John Benjamins Publishing.

Siefring, J. (2004). The Oxford dictionary of idioms: Oxford University Press.

Sinclair, J. M. (1987). Collocation: A progress report (Vol. II). Amsterdam: John Benjamins.

Szczepaniak, R., \& Lew, R. (2011). The role of imagery in dictionaries of idioms. Applied Linguistics, 32(3), 323347. http://citeseerx.ist.psu.edu/viewdoc/download?doi=10.1.1.1031.8230\&rep=rep1\&type=pdf

Thiel, F. (1979). The case for idioms. Die Unterrichtspraxis/Teaching German, 12(1), 21-24. doi:10.2307/3529399

Vasiljevic, Z. (2015). Effects of etymology and pictorial support on the retention and recall of L2 idioms. Electronic Journal of Foreign Language Teaching, 12(1), 35-55. https://e-flt.nus.edu.sg/v12n12015/vasiljevic.pdf

Wood, D. (2010). Formulaic language and second language speech fluency: Background, evidence and classroom applications. Bloomsbury Publishing.

Wray, A. (2000). Formulaic sequences in second language teaching: Principle and practice. Applied linguistics, 21(4), 463-489. https://doi.org/10.1093/applin/21.4.463

Yorio, C. (1989). Idiomaticity as an indicator of second language proficiency. Bilingualism across the Lifespan, 5572. doi: https://doi.org/10.1017/CBO9780511611780.005

Zarei, A. A., \&Rahimi, N. (2012). Idioms: Etymology, contextual pragmatic clues and lexical knowledge in focus. Germany: Lambert academic publishing.

Zhang, L. (2009). The effect of etymological elaboration on L2 idiom acquisition and retention in an online environment (WebCT). Graduate Theses and Dissertations. 11126. https://lib.dr.iastate.edu/etd/11126

Zolfagharkhani, M., \& Moghadam, R. G. (2011). The effect of etymology instruction on vocabulary learning of upperintermediate EFL Iranian learners. Canadian Social $\quad$ Science, 7(6), 1-9. doi:10.3968/j.css.1923669720110706.180 file:///C:/Users/ASUS/AppData/Local/Temp/2090-2535-3-PB.pdf 